\title{
Ossifying Fibromyxoid Tumor of Soft Parts
}

\author{
Report of a Rare Tumor in Kuwait
}

\author{
Nabeel Al-Brahim ${ }^{a}$ Mustafa A. Dashti ${ }^{\text {b }}$

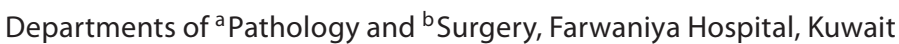

\section{Key Words}

Ossifying fibromyxoid tumor of soft parts - Bone tumors •

Myxoid tumors

\begin{abstract}
Objective: To report a rare case of ossifying fibromyxoid tumor of soft tissue in Kuwait. Clinical Presentation and Intervention: A 60-year-old woman presented with a painless tumor, increasing in size and located in the left buttock, which had been present for an uncertain duration. The patient underwent an excisional biopsy. Pathological examination revealed a $7.5-\mathrm{cm}$ well-circumscribed mass with a lobulated cut surface. Histologically, the tumor was encapsulated by an incomplete shell of lamellar bone. The tumor had variable cellularity, and, in areas, contained myxoid stroma. The tumor cells had eosinophilic cytoplasm with vesicular roundto-oval nuclei. Sparse mitoses were noted. Immunohistochemical stains demonstrated that the tumor cells expressed vimentin, S100 and neuron-specific enolase, with the latter expressed focally. Conclusion: To the best of our knowledge, this is the first case of ossifying fibromyxoid tumor of soft parts to be reported in Kuwait. Therefore, pathologists and clinicians should be aware of this tumor.
\end{abstract}

Copyright $\odot 2008$ S. Karger AG, Basel

\section{Introduction}

Ossifying fibromyxoid tumor of soft parts (OFMT) is a rare neoplasm first described in 1989 [1]. It is a soft tissue tumor of uncertain histogenesis, commonly occur- ring in adults, with a higher incidence in males than females. The extremities and trunk are the most common sites affected [1]. In addition, occurrences in unusual sites, such as the neck and lips, have also been reported $[2,3]$. Typically, OFMT presents as a slow-growing benign mass, which may recur locally or metastasize [4]. In this report, a new case of OFMT diagnosed in Farwaniya Hospital, Kuwait, with immunohistochemical study is presented.

\section{Case Report}

A 60-year-old diabetic and hypertensive woman presented with a painless mass in the left buttock. The tumor was slowly increasing in size, without any overlying skin changes or regional lymphadenopathy. The physical examination revealed a hard, mobile mass that measured approximately $10 \mathrm{~cm}$ in its largest dimension. The lesion was excised.

The gross examination of the resection specimen revealed an encapsulated lobulated tumor, with a smooth external surface that measured $7.5 \times 5.5 \times 4.0 \mathrm{~cm}$; it was hard and difficult to cut. Hemorrhaging and necrosis were not seen (fig. 1). The specimen was X-rayed, and it showed a thin shell of bone within the capsule; no calcification was seen within the parenchyma (fig. 2). Formalin-fixed paraffin-embedded tissues were sectioned at $3 \mu \mathrm{m}$ for hematoxylin and eosin (H\&E) and immunohistochemical staining. Histological examination showed a thick fibrous capsule which extended into the tumor parenchyma dividing it into lobules. Within the capsule, there was a thin, incomplete shell of mature lamellar bone, partially rimmed by osteoblasts (fig. 3). The tumor showed variable cellularity within a myxoid stroma. In areas with high cellularity, the cells were arranged in cords, trabeculae or in a lace-like appearance. The cells had eosinophilic, indistinct cytoplasm and round-to-oval vesicular nuclei. Mitotic counts were less than 2/50 per high-power field (HPF; fig. 4).

\section{KARGER}

Fax +41613061234 E-Mail karger@karger.ch www.karger.com
(C) 2008 S. Karger AG, Basel

1011-7571/08/0174-0340\$24.50/0

Accessible online at:

www.karger.com/mpp
Dr. Nabeel Al-Brahim

PO Box 3313

Salmiya 22034 (Kuwait)

Tel. +965 763 8921, Fax +965 4893078

E-Mail nabeel.albrahim@gmail.com 


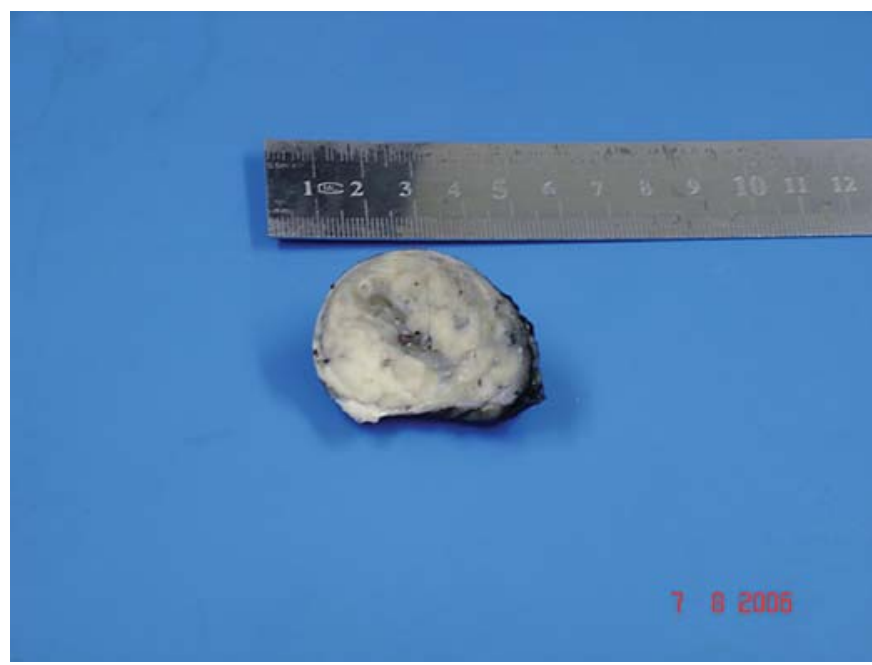

Fig. 1. Gross morphology of the OFMT.

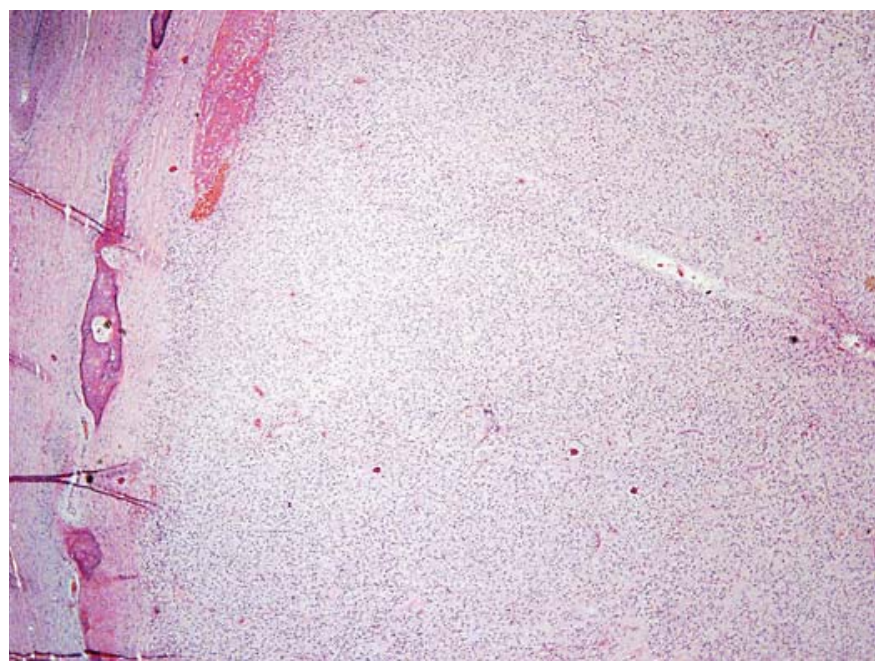

Fig. 3. The OFMT showed peripheral lamellar bone with a myxoid background $(\mathrm{HE}, \times 100)$.

Immunohistochemical stains against antisera antibodies for desmin (1:50, Dako), S100 (1:400, Dako), neuron-specific enolase (NSE; 1:100, Dako), vimentin (1:25, Dako) and CD34 (1:15, Biogenics) were performed at the indicated dilutions. The tumor cells demonstrated positive expression for S100, vimentin and focally for NSE, but were negative for desmin and CD34. The gross morphology, histological findings and immunophenotypical results were diagnostic of OFMT.

Ossifying Fibromyxoid Tumor of Soft Parts

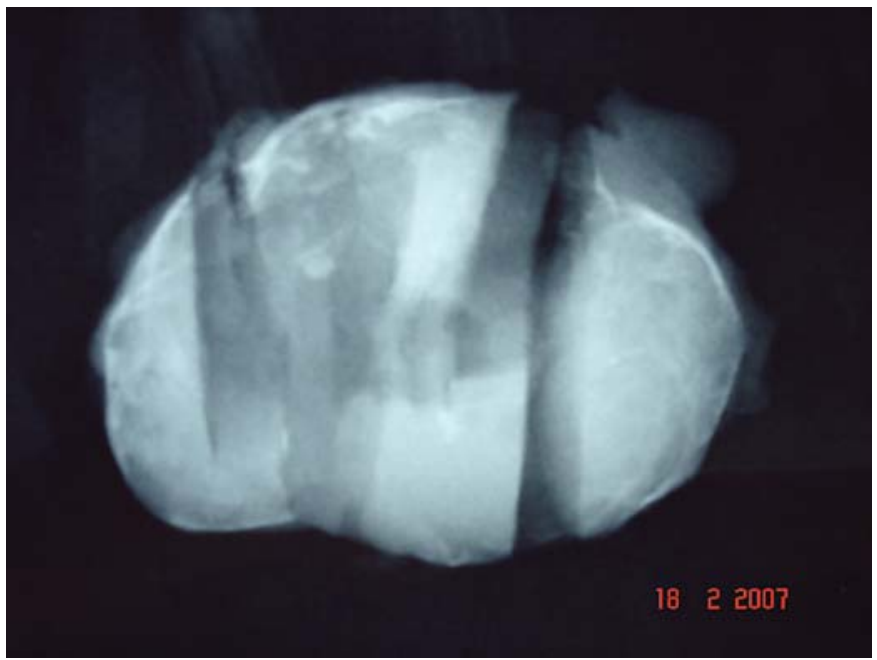

Fig. 2. X-ray of the specimen, demonstrating the peripheral calcification.

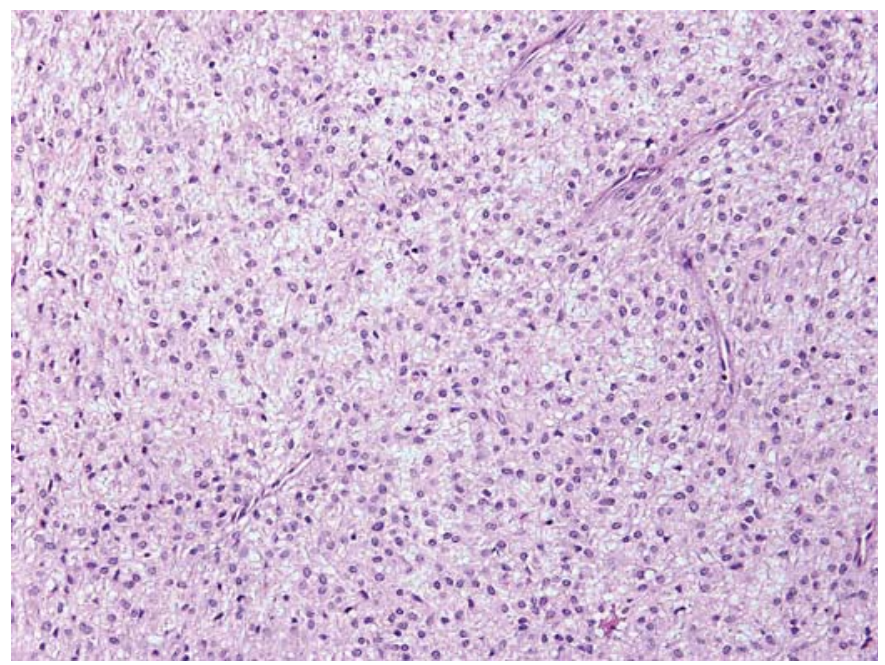

Fig. 4. OFMT: indistinct eosinophilic cytoplasm and bland-looking nuclei $(\mathrm{HE}, \times 400)$.

\section{Discussion}

In this case, the finding of an encapsulated lobulated tumor of eosinophilic spindly cells with vesicular nuclei is as described by previously reported cases $[1,4-6]$. Although the fibromyxoid component of OFMT might suggest a fibroblastic origin, the expression of both S100 and NSE proteins by the tumor cells point instead to a neural origin [1]. Further support for a neural histogenesis is

Med Princ Pract 2008;17:340-342 
provided by the discovery of Holck et al. [6] of an interrupted basal lamina, a Schwannian feature in some of the reported cases $[1,3,7]$, and the demonstration of cytogenetic abnormalities involving chromosomes 6 and 18 also resonated with a malignant peripheral nerve sheath tumor.

Most cases of OFMT are cured by local excision, but up to $1 / 4$ may recur or even metastasize. Statistically, significant factors that may predict recurrence include the size of the tumor, high cellularity, high nuclear grade and mitotic activity. Using these criteria Folpe and Weiss [4] proposed 3 classifications of OFMT: (1) typical OFMT with a low nuclear grade, low cellularity and a mitotic rate $<2 / 50$ HPF; (2) malignant OFMT with a high nuclear grade, high cellularity and a mitotic rate $>2 / 50 \mathrm{HPF}$; (3) atypical OFMT with an intermediate grade between 1 and 2. Our case falls into the typical OFMT class.

\section{Conclusion}

This is the first report of an OFMT in Kuwait. An OFMT is a slow-growing tumor of uncertain, probably neuronal, origin. This tumor commonly behaves in a benign manner. Some of the tumors with high cellularity, high nuclear grade and high levels of mitotic activity tend to have local recurrence and distant metastasis.

\section{References}

1 Enzinger FM, Weiss S, Liang C: Ossifying fibromyxoid tumor of soft parts: a clinicopathological analysis of 59 cases. Am J Surg Pathol 1989;13:817-827.

-2 Lax SF, Ratschek M, Steindorfer P, Langsteger W, Harms D, Beham A: Ossifying fibromyxoid tumor of the neck clinically mimicking a primary neoplasm of the thyroid gland. Path Res Pract 1995;191:57-60.

-3 Schofield JB, Krausz T, Stamp GWH, Fletcher CDM, Fisher C, Azzopardi JG: Ossifying fibromyxoid tumor of soft parts: immunohistochemical and ultrastructural analysis. Histopathology 1993;22:101-112.
Folpe AL, Weiss SW: Ossifying fibromyxoid tumor of soft parts: a clinicopathological study of 70 cases with emphasis on atypical and malignant variants. Am J Surg Pathol 2003;27:421-431.

5 Al-Mazrou KA, Mansoor A, Payne M, Richardson M: Ossifying fibromyxoid tumor of the ethmoid sinus in a newborn: report of a case and literature review. Int J Pediatr Otorhinolaryngol 2004;68:225-230.
Holck S, Pedersen JG, Ackerman T, Daugaard $S$ : Ossifying fibromyxoid tumor of soft parts, with focus on unusual clinicopathological features. Histopathology 2003;42:599-604.

7 Downer LR: Ossifying fibromyxoid tumor of soft parts: evidence supporting Schwann cell origin. Hum Pathol 1992;23:200-202.

$\checkmark 8$ Miettinen M: Ossifying fibromyxoid tumor of soft parts: additional observations of a distinctive soft tissue tumor. Am J Clin Pathol 1991;95:142-149. 